\title{
Exploring the Moves and Steps in TEFL M.A. Theses Introduction and Review of Literature PowerPoint Presentations: A Genre Analysis Approach
}

\author{
Azadeh Pieketaleyee \\ Department of English Language, Rasht Branch, Islamic Azad University, Rasht, Iran \\ Davood Taghipour Bazargani \\ Department of English Language, Rasht Branch, Islamic Azad University, Rasht, Iran
}

\begin{abstract}
The use of technology has had great impacts on different aspects of our lives. Educational settings, in this regard, have been no exception, and technology is changing and affecting the way students learn and present academic endeavors. Among these is the use of computer assisted presentation of materials (PowerPoint in particular) that has received special attention when it comes to presenting the results of research such as students' theses. This study investigates the moves and steps M.A. students of TEFL use in the introduction and review of literature sections while presenting their M.A. theses through PowerPoint. The findings showed that five basic units of M.A. theses (Introduction, Literature review, Method, Results and Discussion) are present as the rhetorical structuring of PowerPoint presentations. The findings of this study can have implications for students, teachers, material developers, curriculum designers and all those who wish to benefit from the genre theory and make use of it practically.
\end{abstract}

Index Terms - CALL, discourse analysis, ESP, genre analysis, move, powerpoint presentation, step

\section{INTRODUCTION}

As a result of the growing interest in higher education for the sake of better educational and job opportunities, the number of articles and papers among university-educated societies is increasing, too. The steady increase in the use of technology has empowered the educationalists and university students to move far beyond the written world and traditional way of presenting the articles and use technology as a powerful way for interaction between the text and audience. Video conferencing, internet and presentation software are samples of this technology. As Corder and UMackey (2011) stated integration of technology into the pedagogical outcomes can resolve pedagogical issues. The use of technological tools requires consideration of its different dimensions. According to Chalhoub-Deville (2002) emergence of computers and undeniable impact of computer technological advances has facilitated the world of foreign language education. Technology can simplify and facilitate the communication purposes of language learning and inject interests and innovations into the area of education.

Computer-assisted language learning (CALL) has many applications on language learning and teaching. PowerPoint Presentations as part of this technology provides its users with different communication tools (Chapelle, 2010). Widespread use of this software in presenting different projects such as class projects, articles, or theses strengthens the necessity of a methodical, step by step analyzing of its features. Effective use of this multidimensional technology reveals a need for its careful consideration from an applied genre study view.

Hammond and Derewianka (2001) have advanced the impact of genre in English for specific purposes (ESP) on increasing the importance of assisting the professionals familiar with the "language required" for communicating in the various academic and communicating setting. As stated by Swales (1990, p. 72), the danger of ignoring genre is precisely the danger of ignoring communicative purpose. Bahatia (1993) has mentioned that any mismatch in the use of generic recourses will be recognized as odd both by the members of the specialist community and the good users of the language.

The fact that teachers are one of the most effective members of every educational system and the wide use of PowerPoint presentation by this group of educational members stress the importance of PowerPoint's genre familiarity for them to be able to keep up with the rapid changes of technology for succeeding in dealing with the communication purposes of the belonging community.

In spite of the fact that PowerPoint presentations as the main way of presenting articles and theses are increasingly being used, few researchers (e.g. Atai \& Talebzadeh, 2012; Rowley-Jolivet \& Carter-Thomas 2005) have considered it from a discourse perspective. 
Although there have been valuable studies which have analyzed the moves and steps of different sections of theses and articles such as Swales' (1990) analysis of introduction section of research articles or Nguyen and Pramoolsook's (2015) analysis of theses' results-discussion chapters, few studies have systematically investigated PowerPoint presentations from a genre perspective. Since the importance of genre familiarity in providing understandable and recognizable presentations is undeniable, the present study attempted to explore the moves and steps of PowerPoint presentations as the means of communication and it focuses on the theses of English language teaching students as the highly expected community to have a considerable amount of genre knowledge for serving their students' communication needs on one hand and dealing with their own community members' professional expectations on the other hand.

\section{LITERATURE REVIEW}

In genre analysis relying on the ESP approach, different kinds of genres such as research articles, theses, lectures, job application letters and sales promotion letters have been of interest for ESP scholars. The framework used for analyzing these genres in many cases followed the Swales' (1990) move analytical model (which he viewed as the most perceptive aspect of applied genre analysis) conducted for the analysis of rhetorical structure of academic texts such as the introduction of research articles. In move analytical model particular attention to the formal characteristics of genres is emphasized (Hyon, 1996; Partlidge, 2007).

More recently, by incorporation of technology into the academic settings, educational members have shifted their attention from paper-based articles to the other forms of presentation which highlighted a growing need in developing digital literacy skills which were defined by Gilster (1997) as the skills needed for communicating with the information presented via computers. CALL as one of the implications of digital literacy emphasized the role of computer in language teaching and learning (Levy, 1997). CALL was later used to refer to any kind of technological innovation embedded in everyday practice and therefore normalized. Alkash and Al_Dersi (2013) referred to PowerPoint presentation as a kind of CALL which provides users with text, images, animation, sound and audio-visual.

This kind of CALL puts demand on the genre analysts to explore its different visual and textual aspects. Investigating on the PowerPoint presentations which were based on the experimental articles, case studies and some other forms of research showed that researchers typically follow a macro-model framework for structuring the main parts of their articles. The macro-model framework consisted of four sections: Introduction, Methodology, Results, and Discussion or Conclusion (Rowley-Jolivet, 2002; Trady, 2005). Each of these sections found by the macro-model framework must be analyzed separately for finding the layers embedded in each which is called Move and Step.

\section{A. Move Analytical Model for Introduction Section}

The moves introduced by Chen and Kuo (2012) for introduction section of research articles are the same as the moves introduced by Swales (1990) for research articles with one extra move. However the steps are not completely the same. These are the moves found by Chen and Kuo (2012): Move IT: Establishing a territory; Move IN: Establishing a niche; Move IO: Occupying the niche; Move IL: Referring to other studies.

\section{B. MIT: Establishing a Territory}

Swales (1990) relates this move to the goal and current capacity. Chen and Kuo (2012) find four steps for it: step ITb or Providing topic generalization/background can be viewed in two forms of statement about knowledge or statement about the phenomena; Step ITc or indicating centrality/importance of topic tries to persuade the members of discourse community that the research is part of a significant and valuable research area; step ITd or defining terms; step IT1 or reviewing previous research in which the author relates what has been found with the finder. The author provides specification of previous findings, researchers and results.

\section{MIO: Occupying the Niche}

As Swales (1990) states move IO or occupying the niche turns the niche established into the research space that explains the present article. It can appear in these steps: Step IOp or indicating purpose/aims/objective; Step IOc or indicating scope of research; Step IOu or indicating chapter/section structure; Step IOh or indicating theoretical position; Step IOw or announcing research/work carried out; Step IOe or describing parameters of research; Step IOq or stating research questions/hypotheses; Steps IOd or defining terms; Step IOm or indicating research method; Step IOr or indicating findings/results; Step IOt or indicating models proposed; Step IOa or indicating applications; Step IOv or indicating value or significance; Step IOj or providing justification; step IOo or indicating thesis structure.

\section{MIL: Referring to Other Studies}

This move which was absent in Swales' (1990) CARS model for Introduction section of research articles can be expressed through three steps: Step ILt or providing background information; Step ILd or providing definition of terms; Step ILj or providing support or justification (Chen \& Kuo, 2012).

\section{E. Move Analytical Model for Literature Review Section}


These are the moves introduced by Chen and Kuo (2012) for literature review section of the investigated master theses: Move LI or introduction which indicates organization of the review chapter and justifies the themes or areas to be reviewed. It doesn't express through any steps; Move LE or establishing one part of the territory of one's own research by; Move LN or creating a research need (in response to previous move) by; Move LO or occupying the research niche by announcing; Move LC or conclusion that provides a summary of the review of the themes and relates the review to the present study.

\section{F. MLI: Introduction}

Chen and Kuo (2012) did not find any steps for MLI and just explained it as a move that indicates organization of the review chapter and justifies the themes or areas to be covered.

\section{G. MLE: Establishing One Part of the Territory of One's Own Research}

Based on Chen and Kuo (2012) these are the steps of this move: Step Len or surveying the non-research related phenomena or knowledge claims; Step LEc or claiming centrality; Step LEr or surveying the research-related phenomena.

\section{H. MLN: Creating a Research Need (in Response to Move LE)}

These are steps introduced by Chen and Kuo (2012) for this move: Step LNc or counter claiming which expresses weaknesses and problems; Step LNg or gap-indicating; Step LNa or asserting confirmative claims about knowledge or research practices surveyed; Step LNr or asserting the relevancy of the surveyed claims to one's own research; Step LNs or abstracting knowledge claims to establish a theoretical position or a theoretical framework; Step LNt or concluding a part of literature review.

\section{MLO: Occupying the Research Niche by Announcing}

Chen and Kuo (2012) found these steps for Move LO: Step LOa or indicating research aims, focuses, research questions or hypotheses; Step LOt or indicating theoretical positions or frameworks; Step IOd or indicating research design or process; Step LOi or interpreting terminology used in the thesis.

\section{J. MLC: Conclusion}

Chen and Kuo (2012) did not introduce any steps for conclusion and just explained it as a move that can provide a summary of the review of the themes and relate the review to the present study.

\section{K. Genre}

Discourse analysts have always been interested in how writing and communicative skills in academic and professional academic setting use the idea of genre to achieve their communicative goals (Johnstone, 2002). Many scholars looked at genre as a framework for analyzing nonliterary discourse for the purpose of serving educational needs such as raising genre awareness for writing compositions, articles and English for specific purposes (Hyon, 1996).

Swales (1990) provided the most practical definition of genre:

A genre comprises a class of communicative events, the members of which share some sets of communicative purposes. These purposes are recognized by the expert members of the parent discourse community and there by constitute the rationale for the genre. This rationale shapes the schematic structure of discourse and influences and constrains choice of content and style. Communicative purpose is both a privileged criterion and one that operates to keep the scope of a genre as narrowly focused on comparable rhetorical action. (p. 58)

Dudley-Evans and ST John (1998) made a distinction between discourse analysis and genre analysis: while discourse analysis refers to any study of language at a level above that of the sentence, genre analysis focuses on the differences between text types. So genre analysis focuses on the frequently occurred structures that distinguish one genre from another. It focuses on the distinguishing features of different texts.

Bhatia (2004) stated that genre analysis as an attempt to study "situated linguistic behavior in institutionalized academic or professional settings" (p. 26) accounts "for not only the way a text is constructed, but also for the way it is often interpreted" (p. 23).

\section{Moves and Steps Analytical Models}

Swales (1990), Dudley-Evans (2000), and Bhatia (1993) referred to move analysis as the most perceptive aspect of applied genre analysis. In move and step analysis, formal characteristics of a special genre are emphasized. Bhatia (2001) defined moves as "rhetorical instruments that realize a sub-set of specific communicative purposes associated with a genre, and as such they are interpreted in the context of the communicative purposes of the genre in question" (p. 84). According to Nwogu (1997), a move is "a text segment made up of linguistic features (lexical meaning, propositional meaning, illocutionary force, etc.) which give the segment a uniform orientation and signal the content of discourse in it" (p. 122). Based on Dudley-Evans and ST John (1998) a move is a "unit that relates both to the writer's purpose and to the content that s/he wishes to communicate" (p. 89).

Moves have their own steps which are parts of the same rhetorical structure and can be viewed as different strategies for realizing the value of moves (Bhatia, 2001). Dudley-Evans and St John (1998) defined step as "a lower level text 
unit than the move that provides a detailed perspective on the options open to the writer in setting out the moves" (p. 89).

Following Swales' move and step model of research articles' analysis and aiming at instructing the students directly on how to compose their own theses, Nguyen and Pramoolsook (2014) worked on electronic Master's theses' introduction chapters written by Vietnamese students in the field of TESOL. The moves they distinguished were the same as Swales' moves in 1990. Nguyen and Pramoolsook (2015) used the same procedure for results-discussion chapters in TESOl master's theses of Vietnamese students and their analysis revealed that the students constructed the texts according their perceived communicative purposes. Except the rhetorical structures of these TESOL thesis chapters in Vietnam, the results of the study also suggested the explicit teaching of the construction of these chapters for genre familiarity because of the insufficient knowledge of these students about this genre.

\section{PowerPoint Presentation}

Kjeldsen (2006) traced the starting point for using media back to 70 s and early $80 \mathrm{~s}$. The age he called "the age of the overhead projector" (p. 2). In 1984, works on an electronic presentation program called Presenter began. The name of Presenter changed to PowerPoint. Despite PowerPoint powerful effects on the teaching, learning and understanding, Kjeldsen (2006) noticed some of its limitations such as "poor resolution and fixed format, its speaker-oriented cognitive style and the bullet points (which are too general)" (pp. 3-6). Facing these hurdles with PowerPoint as a widely used presentation tool in conferences, meetings and academic settings made Kjeldsen suggest that:

The solution to the PowerPoint problem is for us to stop thinking in terms of technology and begin to think rhetorically. As speakers, we should not be thinking of how to fill in a template. We should be thinking of purposes, goals and means. What do we want to achieve? How can we best achieve it? What tools will help us best? And what are the technological limitations and possibilities? If Media Literacy represents the ability to read and interpret media statements, Media Rhetoracy represents the ability to create and communicate such statements. (pp. 11-12)

It seems that from this viewpoint, PowerPoint can be dealt with as a genre. As Rowley-Jolivet (2002) has highlighted the importance of visual channel of communication in scientific presentations, the importance of PowerPoint presentation as one of these most widely used channel can't be neglected.

\section{MATERIAL}

In order to achieve the objective of the present study, a corpus of 50 PowerPoint presentations was collected. These PowerPoint presentations had been prepared by language teaching students of Islamic Azad University, Rasht Branch and based on their M.A. theses. The presentations had been presented in English in short sessions of 15 to 25 minutes in their viva sessions. For the consistency of the results, all the presentations chosen for this study were taken from M.A. students in the field of language teaching.

\section{Procedures for Data Collection AND ANALysis}

This study was conducted between March 2015 and July 2016 and followed a corpus-based approach with its focus on the actual language used in naturally occurring text rather than the possibilities of language. It built on the assumption that textual features of educational discourse in paper-based and computer-based presentations might be different.

The Move analytical model presented by previous researchers was utilized to analyze the PowerPoint presentations presented based on the participants' M.A. theses in this study. As information needed for making these PowerPoint presentations are extracted from relevant paper-based theses, it may be influenced by the cognitive and rhetorical structuring of the written theses process genres. For representing the schematic structure of different sections of the presentations, Chen and Kuo's (2012) move analytical model was adopted. In their model they had found the moves and steps of different parts of Master theses in applied linguistic. For determining the moves' frequency of occurrence, Swales' (1990) cut-off point was used. If a move's occurrence is below $50 \%$ it can be considered as optional and if it is above $50 \%$ it can be considered as obligatory. However instead of the word "obligatory", this study uses the word "conventional" introduced by Kanoksilapatham (2005) for the moves that their occurrence is above the cut-off point.

\section{RESUlts}

In a move analysis, the Introduction and Literature review of the PowerPoint presentations were analyzed manually based on Chen and Kuo's (2012) analytical framework through identification of the moves and steps in each section. Moreover, a comparison was made among these two sections of M.A. thesis PowerPoint presentations with respect to rhetorical structures used to see if the structures are entirely the same for these sections.

\section{A. The Results of the Analyses for the Introduction Section}

Through the genre of the introduction section of the PowerPoint presentations, M.A. students had used different information structure to represent the relevance of their thesis to previous work in the field and their own perspective towards previous research and mentioned the significance, merits, and their justification for their study. 
The results of the move-step analyses revealed that the introductions in fifty theses presentations contained three conventional moves that were establishing a territory, establishing a niche and occupying the niche and one optional move that was referring to other studies. The rhetorical structures of the introduction section of the PowerPoint presentations are summarized in Table 1.

TABLE 1.

RHETORICAL MOVES FOR THE INTRODUCTION SECTION OF THE POWERPOINT PRESENTATIONS

\begin{tabular}{|c|c|c|c|}
\hline & Frequency & Percentage & $\mathbf{N}$ \\
\hline \multicolumn{4}{|l|}{ Move IT: Establishing a territory } \\
\hline Providing topic generalization/background ITb & 43 & 86 & 50 \\
\hline Indicating centrality/importance of topic ITc & 32 & 64 & 50 \\
\hline Defining terms ITd & 23 & 46 & 50 \\
\hline Reviewing previous research ITl & 40 & 80 & 50 \\
\hline Average percent & & $69 \%$ & \\
\hline \multicolumn{4}{|l|}{ Move IN: Establishing a niche } \\
\hline Indicating a gap in previous research $\mathrm{INg}$ & 40 & 80 & 50 \\
\hline Question-raising INq & 10 & 20 & 50 \\
\hline Counter claiming Inc & 8 & 16 & 50 \\
\hline Continuing/extending a tradition $\mathrm{INe}$ & 0 & 0 & 50 \\
\hline Indicating a problem/need Inn & 50 & 100 & 50 \\
\hline Average percent & & $54 \%$ & \\
\hline \multicolumn{4}{|l|}{ Move IO: Occupying the niche } \\
\hline Indicating purposes/aims/objectives IOp & 30 & 60 & 50 \\
\hline Indicating scope of research IOc & 13 & 26 & 50 \\
\hline Indicating chapter/section structure IOu & 30 & 60 & 50 \\
\hline Indicating theoretical position $\mathrm{IOh}$ & 27 & 54 & 50 \\
\hline Announcing research/work carried out IOw & 0 & 0 & 50 \\
\hline Describing parameters of research IOe & 0 & 0 & 50 \\
\hline Stating research questions/hypotheses IOq & 50 & 100 & 50 \\
\hline Defining terms IOd & 42 & 84 & 50 \\
\hline Indicating research method $\mathrm{IOm}$ & 35 & 70 & 50 \\
\hline Indicating findings/results IOr & 6 & 12 & 50 \\
\hline Indicating models proposed IOt & 3 & 6 & 50 \\
\hline Indicating applications IOa & 43 & 86 & 50 \\
\hline Indicating value or significance IOv & 47 & 94 & 50 \\
\hline Providing justification $\mathrm{IOj}$ & 0 & 0 & 50 \\
\hline Indicating thesis structure IOo & 44 & 88 & 50 \\
\hline Average percent & & $61.66 \%$ & \\
\hline \multicolumn{4}{|l|}{ Move IL: Referring to other studies } \\
\hline Providing background information ILt & 21 & 42 & 50 \\
\hline Providing definition of terms ILd & 22 & 44 & 50 \\
\hline Providing support or justification ILj & 19 & 38 & 50 \\
\hline Average percent & & $41.33 \%$ & \\
\hline
\end{tabular}

As it was displayed in Table 1, in general, four moves were identified in the Introduction section. Three of these moves were conventional based on Swales' (1990) cut-off point since the moves' occurrences were above 50\%; and simply the move IL: Referring to other studies was optional based on Swales' (1990) cut-off point as the move's occurrence was below $50 \%$.

These included Move 1: Establishing a territory, conventional, in which steps one, two and four were considered as conventional ( $\mathrm{P}>50 \%$ ). Move 2: Establishing a niche consisted of five steps only two of which (steps one and five) are considered as conventional with 86 and 100 per cent respectively. Move 3: Occupying the niche included 15 steps nine of which were regarded as conventional with step 7 (stating research) having 100\% occurrence.

\section{B. The Results of the Analyses for the Literature Review Section}

In the literature review section of the presentations, M.A. students had used information and evidence to fulfill the aims of their study. Moreover, they had tried to reveal the gap in theory or practice that was important for their inspection, and also made a critical judgment of the previous views, and had indicated the strengths and weaknesses of previous studies. Table 2 summarizes the rhetorical structure of the literature review section of PowerPoint presentations. 
TABLE 2.

RHETORICAL MOVES FOR THE LITERATURE REVIEW SECTION OF THE POWERPOINT PRESENTATIONS

\begin{tabular}{|c|c|c|c|}
\hline & Frequency & Percent & $\mathbf{N}$ \\
\hline \multicolumn{4}{|l|}{ Move LI: Introduction } \\
\hline Indicating organization of the review chapter(s) and justifying the themes (areas)LI & 8 & 20 & 50 \\
\hline \multicolumn{4}{|l|}{ Move LE: Establishing one part of the territory of one's own research } \\
\hline Surveying the non-research-related Len & 28 & 70 & 50 \\
\hline phenomena or knowledge claims /Claiming centrality LEc & 30 & 75 & 50 \\
\hline Surveying the research-related phenomena LEr & 32 & 80 & 50 \\
\hline Average percent & & $75 \%$ & 50 \\
\hline \multicolumn{4}{|l|}{ Move LN: Creating a research need (in response to Move LE) } \\
\hline Counter-claiming (weaknesses and problems) LNc & 16 & 40 & 50 \\
\hline Gap-indicating (paucity or scarcity) LNg & 14 & 35 & 50 \\
\hline Asserting confirmative claims about knowledge or research practices surveyed $\mathrm{LNa}$ & 8 & 20 & 50 \\
\hline Asserting the relevancy of the surveyed claims to one's own research $\mathrm{LNr}$ & 14 & 35 & 50 \\
\hline $\begin{array}{l}\text { Abstracting or synthesizing knowledge claims to establish a theoretical position or a theoretical } \\
\text { framework LNs }\end{array}$ & 6 & 15 & 50 \\
\hline Concluding a part of literature review and/or LNt indicating transition to review of a different area & 10 & 25 & 50 \\
\hline Average percent & & $28.33 \%$ & 50 \\
\hline \multicolumn{4}{|l|}{ Move LO: Occupying the research niche by announcing } \\
\hline Indicating research aims, focuses, research questions or hypotheses LOa & 16 & 40 & 50 \\
\hline Indicating theoretical positions/theoretical frameworks LOt & 18 & 45 & 50 \\
\hline Indicating research design/processes LOd & 18 & 45 & 50 \\
\hline Interpreting terminology used in the thesis LOi & 0 & 0 & 50 \\
\hline Average percent & & $43.33 \%$ & 50 \\
\hline \multicolumn{4}{|l|}{ Move LC: Conclusion } \\
\hline Providing a summary of the review of the themes and relating the review to the present study LC & 6 & 15 & 50 \\
\hline
\end{tabular}

Table 2 showed that, five moves were recognized in the Literature review section of M.A. theses presentations. They included the "Introduction Move" that was related to "Indicating organization of the review chapters and justifying the themes (areas) to be reviewed". Move 1 was related to "establishing one part of the territory of one's own research" while Move 2 was related to "creating a research need". Furthermore, Move 3 included "occupying the research niche"; and the "Conclusion Move" that was related to "providing a summary of the review of the themes and relating the review to their study".

The results of the Move- step analysis showed that from among the five moves found in the Literature Review section only Move 2 that was "establishing one part of the territory of one's own research" and its three steps were conventional $(\mathrm{P}>50 \%)$. The rest four moves were optional with the frequency of occurrence being $20 \%, 28.33 \%$, $43.33 \%$, and $15 \%$, respectively.

Based on the analysis of the introduction and review of literature sections, a framework for M.A. PowerPoint presentation is proposed which is provided in Table 3. 
TABLE 3.

PROPOSED RHETORICAL FRAMEWORK OF M.A. POWERPOINT PRESENTATIONS

\begin{tabular}{|c|c|c|}
\hline & Conventional & Optional \\
\hline \multicolumn{3}{|l|}{ Introduction } \\
\hline \multicolumn{3}{|l|}{ Providing topic generalization/background ITb } \\
\hline Indicating centrality/importance of topic ITc & $*$ & \\
\hline Defining terms ITd & & $*$ \\
\hline Reviewing previous research IT1 & $*$ & \\
\hline Indicating a gap in previous research $\mathrm{INg}$ & $*$ & \\
\hline Question-raising INq & & $*$ \\
\hline Counter claiming Inc & & $*$ \\
\hline Indicating a problem/need Inn & $*$ & \\
\hline Indicating purposes/aims/objectives IOp & $*$ & \\
\hline Indicating scope of research IOc & & * \\
\hline Indicating chapter/section structure IOu & $*$ & \\
\hline Indicating theoretical position $\mathrm{IOh}$ & $*$ & \\
\hline Stating research questions/hypotheses IOq & $*$ & \\
\hline Defining terms IOd & $*$ & \\
\hline Indicating research method $\mathrm{IOm}$ & $*$ & \\
\hline Indicating findings/results IOr & & $*$ \\
\hline Indicating models proposed IOt & & $*$ \\
\hline Indicating applications IOa & $*$ & \\
\hline Indicating value or significance IOv & $*$ & \\
\hline Indicating thesis structure IOo & $*$ & \\
\hline Providing background information ILt & & $*$ \\
\hline Providing definition of terms ILd & & $*$ \\
\hline Providing support or justification ILj & & $*$ \\
\hline \multicolumn{3}{|l|}{ Review of literature } \\
\hline Indicating organization of the reviewchapter(s) and justifying the themes (areas)LI & & $*$ \\
\hline Surveying the non-research-related Len & $*$ & \\
\hline phenomena or knowledge claims Claiming centrality LEc & $*$ & \\
\hline Surveying the research-related phenomena LEr & $*$ & \\
\hline Counter-claiming (weaknesses and problems) LNc & & $*$ \\
\hline Gap-indicating (paucity or scarcity) LNg & & $*$ \\
\hline Asserting confirmative claims about LNa knowledge or research practices surveyed & & $*$ \\
\hline Asserting the relevancy of the surveyed LNr claims to one's own research & & $*$ \\
\hline $\begin{array}{l}\text { Abstracting or synthesizing knowledge LNs claims to establish a theoretical position or a } \\
\text { theoretical framework }\end{array}$ & & $*$ \\
\hline Concluding a part of literature review and/or indicating transition to review of a different area LNt & & $*$ \\
\hline Indicating research aims, focuses, research questions or hypotheses Loa & & $*$ \\
\hline Indicating theoretical positions/theoretical frameworks Lot & & $*$ \\
\hline \multicolumn{3}{|l|}{ Table 4.6. (continued) } \\
\hline Indicating research design/processes LOd & & $*$ \\
\hline Providing a summary of the review of the themes and relating the review to the present study LC & & $*$ \\
\hline
\end{tabular}

\section{CONCLUSION}

This study produced results which corroborate the findings of the previous work in this field. These findings are in agreement with Atai and Talebzadeh's (2012) findings which showed PowerPoint presentations of conferences in applied linguistic contain the same sections of the relevant articles. The results are in line with Chen and Kuo's (2012) study, too. However, because the present study investigated on the presentations instead of the paper-based theses, less moves and steps were found in comparison to Chen and Kuo's study. The time limitations of a viva session, having audiences' attention and interest and not having a clear framework for preparing the presentations might be some reasons of these differences.

To analyze the Introduction section of PowerPoint presentations a scheme of three sequential moves and one independent move, consisting of 27 steps in total, was used. The framework taken from Chen and Kuo (2012) is similar to Swales' (1990) three moves CARS model with an extra move as "referring to other studies". The structures of Introductions in the present study generally follow Chen and Kuo's (2012) model, but with fewer steps under the moves.

Some of the steps introduced by them were completely missing in the presentations such as "continuing a tradition" of the second move and "announcing research carried out" and "describing parameters of research" of the third move. This could be because of the time limitation of the viva session which makes students include only main parts of the theses in the presentations. The majority of the presentations included Move 1 (IT) "establishing a territory" which is in line with Atai and Talebzadeh's (2012) results about PowerPoint presentations of research articles which can indicate that stating the goal and current capacity is of great importance for slide makers. It also confirms Chen and Kuo's (2012) results about M.A. theses. However Chen and Kuo reported a higher frequency for Move 1. The frequencies of Move 2 (IN) and Move 3 (IO) were also similar to what Atai and Talebzadeh (2012) reported. The occurrence of Move 3 (IO) was more than Move 2 (IN) and less than Move 1 (IT). It may be due to the fact that students prefer to investigate on 
their research area by occupying the niche than focusing on the other studies to find a gap in them or indicate problems which make the present study necessary.

Regarding the sequence of the steps some differences were observed between the results of the present study and Chen and Kuo's results. In two presentations step "announcing research carried out" was seen at the beginning of presentation which is not a normal order of occurrence of IOw. The Move 4 or "referring to other studies" had the lowest frequency among the presentations and did not follow the sequence introduced by Chen and Kuo (2012) as it was not viewed as separated parts or in isolated slides in any of the presentations. The occurrence of this move was distributed among other slides of the Introduction.

Literature review section was analyzed through three sequential moves and two independent moves and their related steps (16 steps in total). Unlike chen and Kuo (2012) which had reported a frequency of $100 \%$ for the Move LI or "introduction" and a high frequency for the Move LC or "conclusion", the results revealed that very few presentations had these two moves. That may be because of the fact that these two parts in each chapter are obligatory for the writers of thesis while the students don't have to include an "introduction" and "conclusion" or "summary" at the end of each part of the presentations. It seems that presenters don't want to lose the audiences' attention with loading them with too much information. In addition the limited time of viva session doesn't let them to include all parts of Chapter two as the longest chapter of a thesis in the presentations. This may be a reason for the limited numbers of slides devoted to Literature Review in the presentations (maximum three slides).

The frequency of Step LEn or "surveying the non-research related phenomena or knowledge claims", Step LEc or "claiming centrality" and Step LEr or "surveying the research-related phenomena" indicates that Move LE enjoys the highest frequency among the moves of this chapter. However, the frequencies of three step sequence patterns were generally low, suggesting that they do not always exist a fixed way. Chen and Kuo (2012) had reported similar results about Steps LEn and LEr.

Having emphasized the importance of genre familiarity, the results of the present study can help the graduate students of English teaching to prepare more comprehensible presentations for their viva session. Well-organized presentations would be able to communicate much easier with the audience in comparison to those that are made haphazardly, as comprehension can be greatly improved if more attention is paid to the rules of the relevant genre. In addition, the results of this study about the ever-growing genre of PowerPoint presentations can help these graduate students as future teachers enrich their genre knowledge's source and transfer it to their own students in the future.

Some clear implications can be drawn from this study for the lecturers and professors to support their students with the knowledge of PowerPoint presentations as the genre of technology in the process of writing their theses and preparing slides based on them. By drawing students' attention to the relationship between the written theses genres and the genre of PowerPoint presentations, they can assist them with the necessary genre knowledge and support them for providing their audience with highly effective and interactive presentations.

It is hoped that he results of this study provide material and curriculum developers with theoretical information about this genre. Materials which contain theoretical information about different genres can be of great importance for learners and teachers and therefore may help the material developers reach a career progression through the systematic gathering of such information in electronic or paper-based materials. By the use of the information extracted from such studies, curriculum developers and syllabus designers can provide the learners and teachers with the information about genre of technology and shorten the distance between theory and practice by including this information in the process of education.

The present study investigated the written form of PowerPoint genre. Accordingly, visual elements that play a very communicative role remained underexplored. With analyzing visual characteristics of the presentations and verbal and non-verbal communicative behaviors of the presenters beside rhetorical features of the presentations in other studies, audience will be provided with more complete information about this genre and the way it achieves its goals. Other researches can also be conducted in different academic settings except Islamic Azad Universities. Different studies can be carried out with more samples, presentations taken from different fields and different levels. This study ignored the gender of presenters and its possible effects on the preferences of them in the process of slide making. It might be beneficial to take the effect of this demographic variable on the language and discoursal preferences into the account in other studies.

This study attempted to describe the moves and steps in introduction and review of literature sections of PowerPoint presentations of M.A. students in the field of teaching English as a foreign language at Islamic Azad University, Rasht Branch. Findings showed the existence of some shared structures among the presentations that were preferred by the students to achieve the communicational needs of their discourse community and be effective members of their academic settings. The findings also showed some differences between PowerPoint presentations as a manifestation of CALL and M.A. theses as written form genres.

\section{REFERENCES}

[1] Alkash, K. A. M., \& Al-Dersi, Z. E. M. (2013). Advantages of using PowerPoint presentation in EFL classroom. International Journal of English Language \& Translation Studies, 1, 3-16. 
[2] Atai, M. R., \& Talebzadeh, H. (2012). Exploring visual and textual discourse of applied linguistics PowerPoint conference presentations. ESP across Cultures, 9, 7-26.

[3] Bhatia, V. K. (1993). Analyzing genre: Language use in professional settings. New York: Longman.

[4] Bhatia, V. K. (2001). Analyzing genre: Some conceptual issues. In M. Hewings (Ed.), Academic writing context (pp. 70-92). Birmingham: University of Birmingham.

[5] Bhatia, V. K. (2004). Worlds of written discourse. London: Continuum.

[6] Chalhoub - Deville, M. (2002). Technology in standardized language assessments. In R.B. Kaplan (Ed.), The Oxford handbook of applied linguistics (pp. 471-480). Oxford: Oxford University Press.

[7] Chapelle, C. A. (2010). The spread of computer-assisted language learning. Language Teaching, 43(01), 66-74.

[8] Chen, T.-Y., \& Kuo, C.-H. (2012). A genre-based analysis of the information structure of master's theses in applied linguistics. The Asian ESP Journal, 8(1), 24-52.

[9] Corder, D. M. U-Mackey, A. (2011). Integration of technology for effective learning, teaching and assessment. World CALL: International Perspectives on Computer-Assisted Language Learning, 5, 188-201.

[10] Dudley-Evans, T. (2000). Genre analysis: a key to a theory of ESP? Ibérica: Revista de la Asociación Europea de Lenguas para Fines Específicos (AELFE), (2), 3-11.

[11] Dudley-Evans, T., \& St John, M. J. (1998). Developments in English for specific purposes: A multi-disciplinary approach. England, Cambridge: Cambridge University Press.

[12] Gilster, P. (1997). Digital literacy. New York: John Wiley \& Sons.

[13] Hammond, J., \& Derewianka, B. (2001). Genre. In D. Nunan \& R. Carter (Eds.), The Cambridge Guide to Teaching English to Speakers of Other Language (pp. 186-193). Cambridge: Cambridge University Press.

[14] Hyon, S. (1996). Genre in three traditions: Implications for ESL. TESOL Quarterly, 30, 693-722.

[15] Johonstone, B. (2002). Discourse analysis. United Kingdom: Blackwell.

[16] Kanoksilapatham, B. (2005). Rhetorical structure of biochemistry research articles. English for Specific Purposes, 24(3), 269292. doi: $10.1016 /$ j.esp.2004.08.003

[17] Kjeldsen, J. E. (2006). The rhetoric of powerpoint. International Journal of Media, Technology and Lifelong Learning, 2(1), 117.

[18] Levy, M. (1997). Theory - driven CALL and the development process. Computer Assisted Language Learning, 10(1), 41-56.

[19] Nguyen, T. T. L. \& Pramoolsook, I. (2015). Move analysis of Results-Discussion chapters in TESOL master's theses written by Vietnamese students. 3L; Language, Linguistics and Literature, the Southeast Asian Journal of English Language Studies, $21(2), 1-15$

[20] Nwogu, K. N. (1997). The medical research paper: Structure and function. English for Specific Purposes, 16(2), 119-138.

[21] Paltridge, B. (2007). Approaches to genre in ELT. In J. Cummins \& C. Davison (Eds.), International handbook of English language teaching (pp. 931-943). New York, NY: Springer.

[22] Rowley-Jolivet, E. (2002). Visual discourse in scientific conference papers: A genre-based study. English for Specific Purposes, 21(1), 19-40.

[23] Rowley - Jolivet, E., \& Carter - Thomas, S. (2005). The rhetoric of conference presentation introductions: context, argument and interaction. International Journal of Applied Linguistics, 15(1), 45-70.

[24] Swales, J. M. (1990). Genre analysis: English in academic and research settings. Cambridge: Cambridge University Press.

[25] Tardy C. M. (2005). Expressions of disciplinarity and individuality in a multimodal genre. Computers and Composition, 22(3), 319-336.

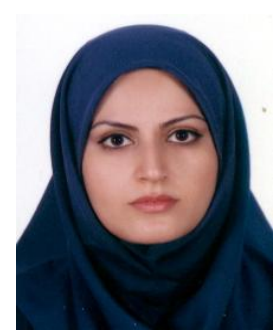

Azadeh Peiketaleyee is holding an M.A. degree in TEFL from Islamic Azad University, Rasht branch, Iran. She has more than 10 years of experience in Teaching English as a Foreign Language to Iranian young and adult students in intermediate level, advanced level, and IELTS preparatory courses. His fields of interest and research are mainly "Discourse analysis", "Genre analysis", and ESP. Ms. Peiketaleyee is currently working as an official IELTS instructor in various private institute in Rasht, Iran. E-mail: Azadeh_Peiketaleyee @YAHOO.com

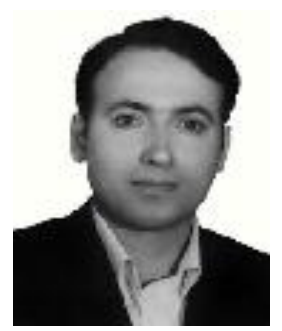

Davood Taghipour Bazargani is holding Ph. D degree in TEFL from Kharazmi University, Tehran, Iran. $\mathrm{He}$ has more than twenty years of experience in Teaching English as a Foreign Language to Iranian university students and young learners in private institutes. His research interests are "Critical cultural awareness", "Materials development", and "CDA".

Dr. Bazargani is currently an assistant professor of TEFL at Islamic Azad University, Rasht Branch, Iran. E-mail: Bazargani74@YAHOO.com 